\title{
New Typologies of Contemporary Shopping Malls in Egypt
}

\author{
Karim W. F. Youssef \\ Mount Royal University, Canada \\ kyoussef@mtroyal.ca
}

\begin{abstract}
Contemporary shopping malls in Egypt have created new public spaces for lifestyle and leisure, which complement the commercial logic of consumer behaviour. Mega malls in Egypt are simultaneously merging shopping, leisure, and entertainment, creating an ambivalence. They are representations of the globalized economy, but also manifest a certain uniqueness through their typology, their mode of insertion in the urban fabric and the type of public spaces created in them. This paper traces four new typologies in the design of six mega shopping malls in Egypt, constructed since 2010, as they integrate new public gathering spaces for leisure, recreation, and entertainment. Data on the new malls in Egypt was collected from corporate websites and promotional brochures, Google Maps and Street View, TripAdvisor, social media websites, visitor comments and news articles. A key finding is the trend of integration of large outdoor recreational spaces such as courtyards and plazas in mall design, the inclusion of a water element for attraction as well as the transition in function from simply offering goods and services to one that offers experiences and events to encourage recurring visits to the mall. The transformation of the mall parallels changes in conceptualizing the city of the $20^{\text {th }}$ century as a large marketplace, an emporium of consumption, to conceptualizing the city of the $21^{\text {st }}$ century as a large theatre and a festive place.
\end{abstract}

Keywords: megamalls, quasi-public space, hybridization, satellite cities, lifestyle shopping

To cite this article:

Youssef, K. W. F. (202I) New Typologies of Contemporary Shopping Malls in Egypt, The Journal of Public Space, 6(I), 95-I22, DOI I0.3289I/jps.v6il.I303

This article has been double blind peer reviewed and accepted for publication in The Journal of Public Space.

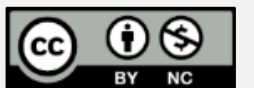
This work is licensed under a Creative Commons Attribution - Non Commercial 4.0 International License https://creativecommons.org/licenses/by-nc/4.0/ 


\section{Introduction}

The overall design typology of a shopping mall does not differ much across the globe. It is a very familiar environment that caters to tourists and global citizens. It joins other building types that are globally homogenized such as hotels, resorts, gated communities, airports, etc. The shopping mall is detached spatially, socially, and culturally from its immediate context. Despite being conceptualized as a form that evolved from its predecessor - the department store - that was integrated within the city, the detachment of the shopping mall has 'satellized' the city (Baudrillard, 1994; Clarke, 2003) creating 'a city within a city' where "[s]hopping does not take place within the city; the city takes place within shopping" (Miles, 2012, p. 84). The shopping mall created a new quasi-public space in the city where the shopper is enclosed in a self-contained and irresistible environment.

From a cultural perspective, the space of the shopping mall leads to cultural hybridization, hybridity in consumerism, hybridity in mass culture and everyday habits, hybridization of food. It is the creation of something new, an American culture fused with the local culture. A shopping mall in Egypt is also a place of social and cultural escape. Abaza (200I) points out how teenagers flock to malls to escape the purview of their parents and how women escape their conservative societies and patriarchal dominance by fleeing to the shopping mall. In such a sense, the mall is a gendered space and a place of refuge, a world of fantasy that visitors frequent to purchase hope and create aura (Jacobs, 1984).

The shopping mall is paradoxically a modern building type invented in the U.S. yet at the same time an archetype of the postmodern city (Clarke, 2003; Miles, 2012; McGreevy, 2018). The mall is a space of consumption, a controlled and sanitized environment, a simulated and themed environment, a Foucauldian heterotopy, an illusory space, a phantasmagorical environment (Miles, 2012). A positive aspect of the postmodern environment of the shopping mall is its inclusive character and pluralism. Nevertheless, shopping malls have been criticized for creating exclusive spaces for higher income groups (Carmona, 20l0).

The proliferation of shopping malls is a testament to the physical domination of consumption upon the urban fabric (Miles, 20I2). Shopping malls are usually enclosed spaces that are oriented internally around a skylit atrium or food court. They are characterized by an introverted architecture where the façade turns its back to the surroundings while at the same time the interior creates an attractive ambiance for the flaneur to see and be seen. The shopping mall creates an exclusionary environment that invites upper echelons of society, middle- and upper-class consumers while excluding the lower-class and the poor. The shopping mall is also a place of construction of cultural identities and hybridization of cultural norms of tourists with local visitors, a hybridization induced by new styles and trends that are promoted in international stores dotting the mall.

This paper investigates and analyses the design of six mega shopping malls in the Greater Cairo Region erected during the last decade, that integrate new public gathering spaces for social interaction, leisure, recreation, and entertainment. The main research question that guides this paper is: How has inclusivity been enhanced by the introduction of outdoor public gathering places and the integration of leisure and entertainment functions in the design of the shopping mall. The objective of the paper is to understand the shift in place-making strategy in the form and function of malls while 
linking these changes with the quality of place experienced by users of the mall. The research is exploratory with the aim of shedding light on new trends in the Middle East in the creation of new landscapes of high-end consumption.

\section{Methodology}

The paper captures the major shopping mall projects in Egypt constructed since 2010 to the present. A short description is provided for each mall to give some background information on the mall. User experience was collected from social media websites and comments were collected from TripAdvisor. Photos, floor plans and maps were collected from corporate websites, Google Maps, Street View, and Foursquare User Guide. Maps helped in understanding the layout of each mall and its insertion in the urban fabric. Floor plans showed the different functions of spaces in the mall, their location in the architectural program, and areas designated as open space. A schematic diagram of each mall was constructed by the researcher to simplify the categorization of the typology of the mall.

\section{Emergence of shopping malls in Egypt}

When Victor Gruen envisioned the shopping mall, he conceptualized it as a community centre to counteract the unliveliness of the suburbs. Victor Gruen realized that the North American suburban 'desert' needed to reify communitarian values through a new building type, a shopping centre organized around a pedestrian mall to solve the problem of suburban environments in North America. The shopping centre was an agent of recentralization (Miles, 20I2) and re-agglomeration (McGreevy, 20I8), a multipurpose centre that integrated commercial activities with cultural and entertaining activities as well as social events. However, the communitarian values envisioned by Gruen boiled down to the demands of a consumer capitalism. The variety of shops and services that would cater to the needs of suburban residents became reduced to luxury shopping and a commercial formula set on making the most profit, the single-bottom line. The subsequent recreationalization of shopping malls has also stripped it of its communal function (Miles, 20I2).

Despite being an American invention and global archetype, shopping malls do not necessarily fulfil the same functions in the Middle East, Southeast Asia, or Latin America (Abaza, 200I; Dávila, 2016). Although shopping malls across the globe look the same physically, they are differentiated socially by the demographics of patrons going to the mall. location of the mall within the city, proximity to affluent or low-income neighbourhoods, as well as local variations due to different settings and other uses in proximity to the mall. Egyptian malls are not only for shopping purposes but also meeting places especially on weekends and holidays for whole families and teenager groups. Shopping malls in Egypt have created new public spaces for leisure which complement the commercial logic of consumer behaviour centred on strolling and vitrine shopping. While contemporary shopping malls in Egypt are representations of the globalized economy, they also manifest a certain uniqueness through their typology, their mode of insertion in the urban fabric and the type of public spaces created in them. "In Egypt, there has been a reshaping of public space to merge mall shopping with leisure (movie houses, billiard rooms, discotheques, ice-skating rinks).” (Abaza, 200 I, p. 
107). The mall is simultaneously merging shopping, leisure, and entertainment, creating an ambivalence.

For example, the first typology of insertion of shopping malls in Egypt was their construction near popular markets such as the insertion of the Cairo World Trade Center in 1990 within the popular quarter of Boulaq, near Boulaq market (Abaza, 200I). As Abaza notes, the World Trade Centre in Cairo has a new conception of shopping as leisure space with a central atrium open space, designed symbolically in the form of a covered popular market, a 'wekala', with wooden screens. This typology appears as the juxtaposition of two types, the traditional market that is integrated with the surrounding social and physical fabric of the city and the modern mall that is detached from the surrounding social and physical environment, a detachment and privatization of space that has caused gentrification and the dislocation of the poor. Other examples by Abaza (200I) are the Yamama Center in Zamalek district, the first mall ever constructed in Cairo in 1989, malls constructed in the mid- and late-1990s in Nasr City (e.g. Geneina Mall - 12,000 m², Tiba Mall (also known as al-Aqqad Mall) $30,000 \mathrm{~m}^{2}$ and al-Sirag Mall $-14,000 \mathrm{~m}^{2}$ ), and the First Giza Mall in the district of Giza. The Yamama Center is a vertical mall with nine floors and GLA $4,000 \mathrm{~m}^{2}$ whose main patrons were students from nearby faculties as well as Saudis and visitors from the Gulf area. The malls in Nasr City had cinemas, coffee shops, bowling and billiard rooms, video and laser games, a gym, mega screens, a skating rink, and children's game arcades (Abaza, 2009). Some of the malls in Nasr City also included residential apartments at higher levels above the shopping spaces. While Tiba Mall attracts families, Geneina Mall attracts teens and youth. The First Giza Mall was constructed in 2013 and covers over $10,000 \mathrm{~m}^{2}$ of retail space in 3 floors with 60 upscale boutiques stores for the luxury shopper and one restaurant. The First Mall is considered Egypt's capital for high end international brands such as Bulgari, Rolex, Omega, Tiffany \& Co, Bally, Zegna and Paul \& Shark. La Gourmandise Brasserie, a cafeteria in the middle of the airconditioned mall, surrounds a fountain and a catwalk for fashion shows. It caters mainly to Persian Gulf Arab customers (Abaza, 2009).

\section{Contemporary Mega Shopping Malls in Egypt}

Shopping centres in Egypt have transitioned from a vertical multi-storied urban mall (organized around an enclosed central atrium and integrated in a wider commercial residential development with office towers and hotels), inserted close to traditional markets and popular low-income neighbourhoods to a horizontal suburban mega mall inserted in new satellite cities like New Cairo and 6th of October City for high-income and upper-class suburban residents. These social spaces for public gathering are new focal points in these newly built cities and have siphoned out liveability of open public spaces in nearby neighbourhoods (Elhusseiny and Kesseiba, 2019). Built along the ring road and major transport corridors, the new mega malls are accessible mainly by car and are designed as destination places for leisure, recreation, and entertainment alongside shopping. Built in the desert, mega malls in Egypt are influenced by the design of malls in the Gulf Area especially those malls that were designed by the same private corporation, Majid Al-Futtaim Group, that expanded its operation of malls in Dubai and Abu Dhabi to encompass cities in Egypt and other middle eastern countries in the 
region. For instance, it is not by coincidence that the Mall of Egypt has an indoor skiing area following the same imported model of the Mall of Emirates in Dubai.

Egypt has witnessed an increase in the number and size of shopping centres over the past three decades. The 1990s could be called the decade of malls in Egypt with a record of 24 malls in Greater Cairo by 2003 (Abaza, 2009). Regulatory changes in Egypt in 2004 and deep cuts in Customs duties opened Cairo to international consumer goods. Luxury retail emerged in Cairo on a significant scale in late 2005 (Group, 2010). Cairo's first international-standard shopping mall, City Stars Mall, was the biggest mall in 2005. City Stars is a vertical multi-story mall with $150,000 \mathrm{~m}^{2}$ gross leasable area, $70,000 \mathrm{~m}^{2}$ of retail space for over 650 multinational stores and local boutiques, a 14,000 $\mathrm{m}^{2}$ hypermarket, two indoor theme parks, a $2 \mathrm{I}$-screen multiplex cinema, a modern indoor market that is a simulation of the bazaar Khan el Khalili, three hotels, a food court, and a large exhibition space. Following City Stars was Cityscape Mall in 2010, a multi-story shopping centre, four floors, with informal eateries, open air terraces, restaurants, a food court, total area $21,000 \mathrm{~m}^{2}, 100$ commercial shops, a $2000 \mathrm{~m}^{2}$ hypermarket, artificial lake of $2000 \mathrm{~m}^{2}$ for occasional festivals and celebrations.

Thereafter, four mega shopping malls were constructed in the years 2010 to 2017, with gross leasable areas between 100,000 to 200,000 $\mathrm{m}^{2}$. They are Mall of Arabia in 2010, The District Mall in 2014, Cairo Festival City in 2013, the Mall of Egypt in 2017, and City Centre Almaza in 2019. A sixth mega mall, Cleopatra Mall, is currently under construction. A seventh mega mall, Katameya Downtown Mall in New Cairo will be added to the list in 202I with a GLA of $110,000 \mathrm{~m}^{2}$ for 230 retail shops and 32 cafes \& restaurants. The construction of other internationally modelled malls north of Cairo, in the Delta region, are also starting to proliferate such as the Mall of Tanta, completed in 2019 with GLA 40,000 $\mathrm{m}^{2}$, and Mall of Mansoura, to be completed in 2021 with GLA $50,000 \mathrm{~m}^{2}$.

This paper traces new typologies in the design of mega shopping malls in the Greater Cairo Region as they integrate new public gathering spaces for leisure, recreation, and entertainment. A major trend is the integration of large outdoor recreational and dining areas as well as a transition from simply offering goods and services to one that offers experiences and events to encourage recurring visits to the mall. The layout for mall designs and functional spaces was referenced from websites of each mall except for the District Mall whose website was still under construction. Google Maps was also a source of information for mall layouts, 3D views and street view photos. Other websites such as social media sites (Facebook and Twitter) and Trip Advisor were also used to gather information on events, promotional videos, and customer reviews.

\section{Mall of Arabia}

Description / Background

The Mall of Arabia, constructed in 2010 with more than 200 stores and GLA I 1 0,000 $\mathrm{m}^{2}$, has a recent extension called The Expansion, a luxury retail section (see lower section of Figure I) with premium end brands on par with what a shopper would experience internationally, with shops having 12 m frontages rather than the typical $6 \mathrm{~m}$, a food hall, and a park. Mall of Arabia recently announced the opening of a drive-in cinema, which will be the first of its kind in Egypt. Numerous drive-in entertainment venues like cinemas and concerts have been introduced in response to the spread of 
the global coronavirus pandemic. Mall of Arabia's main anchors are Spinney's hypermarket, a Cinema-plex, and an indoor play area, Billy Beez, with reverse bungy jump and a nearby entertainment 7D Simulator for an immersive cinematic experience. In the heart of The Expansion is a large courtyard that offers an outdoor space for public gathering. The courtyard contains a park, having an area of eight acres, that expands the experience of outdoor lifestyle shopping (see Figure I) while including an outdoor kids' zone and a large playground for children (see Figure 2).

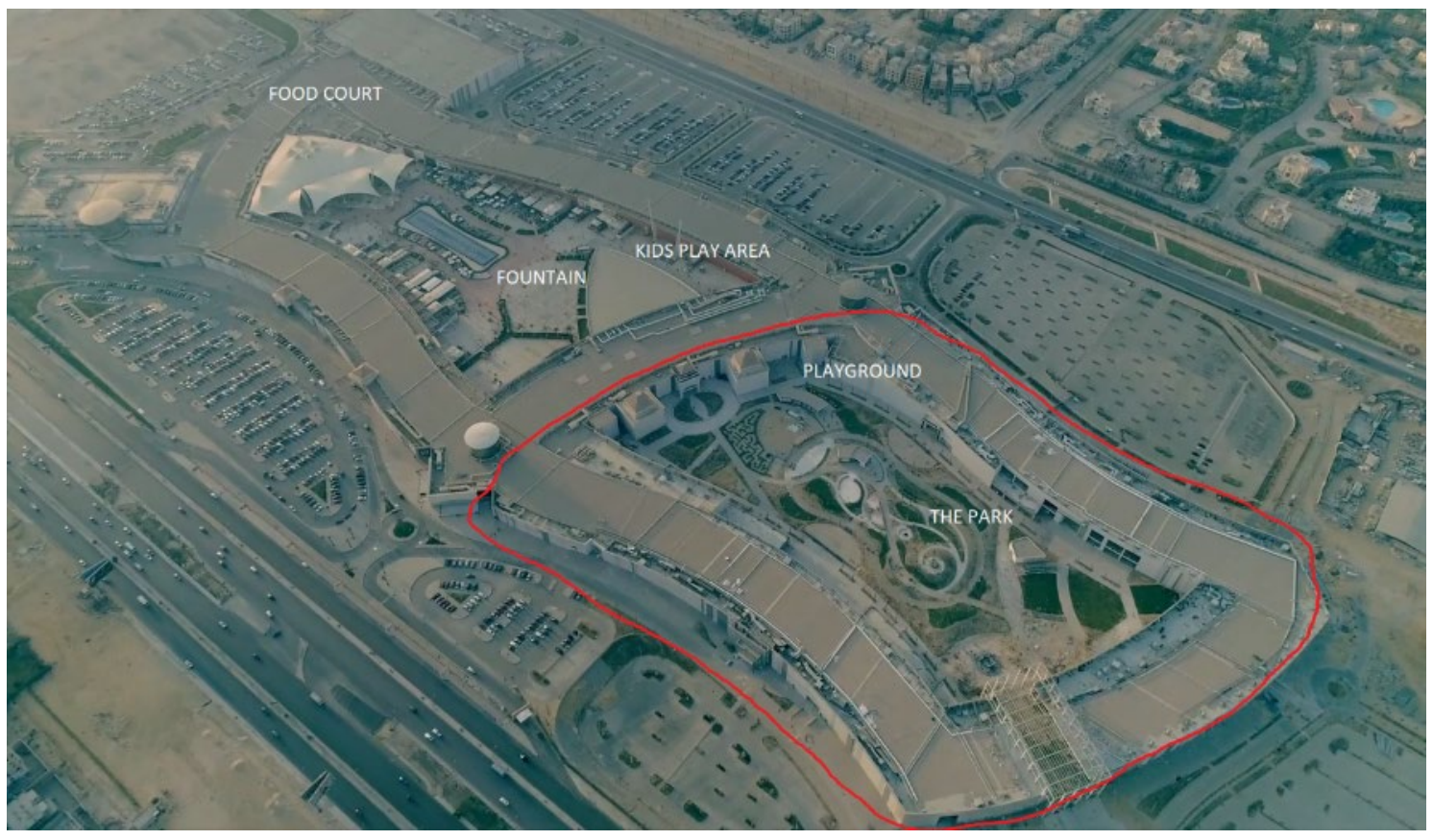

Figure I. Bird's eye view of Mall of Arabia showing the extension surrounding The Park. (Source: Marakez Egypt, author annotation overlay)

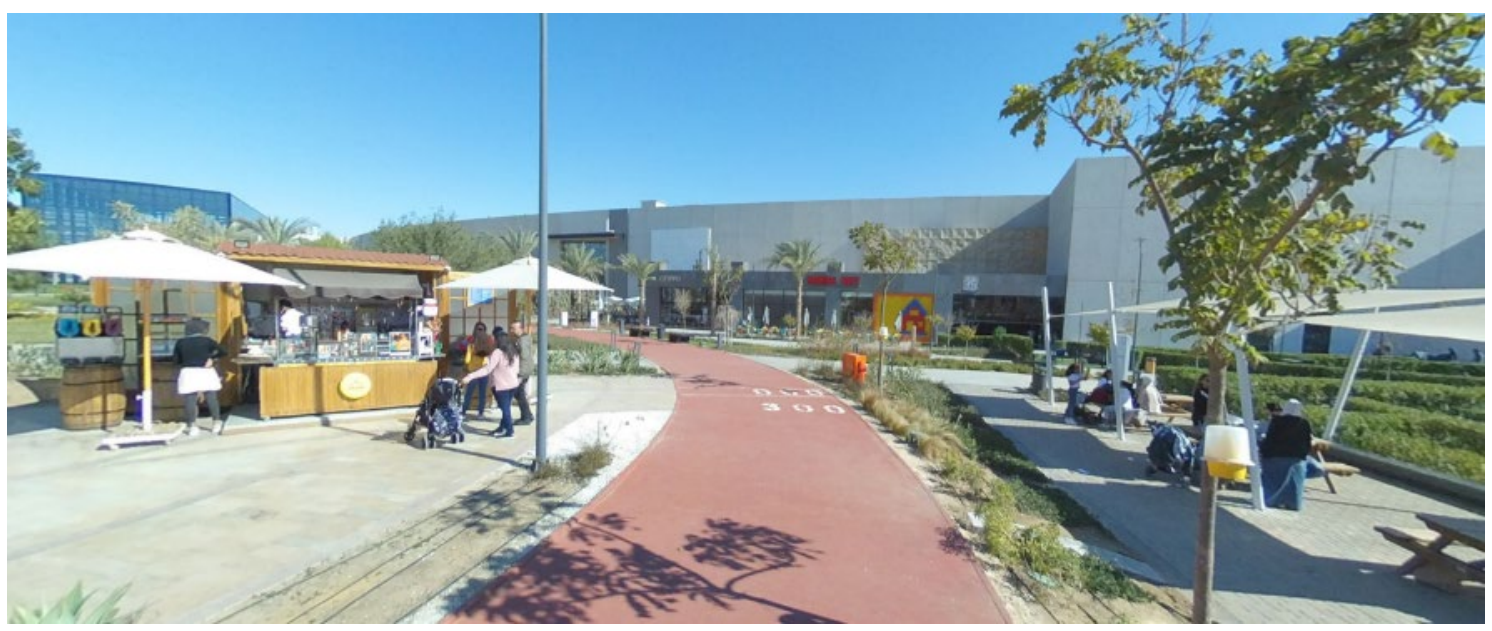

Figure 2. The Park at Mall of Arabia offering an outdoor lifestyle shopping in a park setting within a courtyard extension of the mall. The figure shows the running track. (Source: Google Maps Street View) 
The Park has frequent events and live music on weekends to keep kids engaged. It is the first mall in Egypt to include a landscaped park as part of the mall experience with platforms for yoga practice and a running track for recreational sport activity. The goal is creating a lifestyle experience that positively impacts the community other than typical mall shopping. There is a coffee shop called Qahwa, which literally means coffee, overlooking the playground where parents could enjoy sitting, chatting, and sipping a coffee while observing their kids.

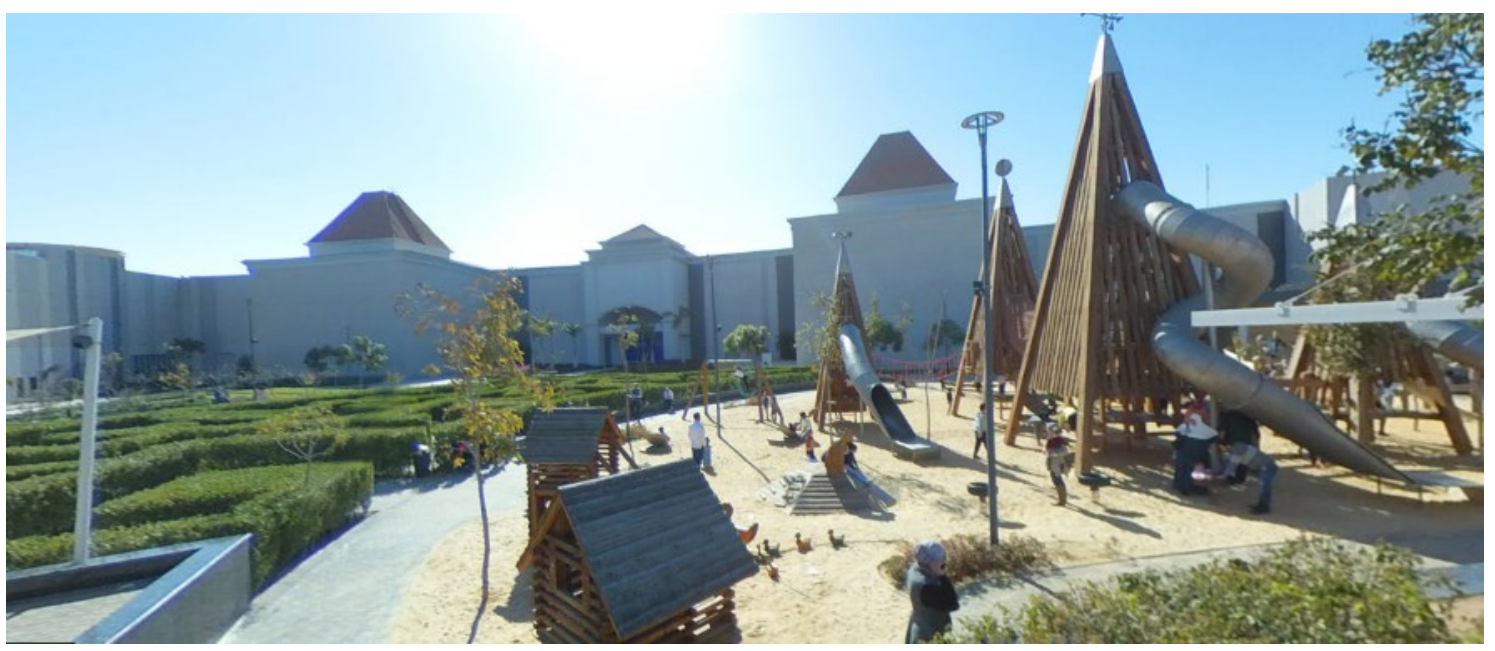

Figure 3. An outdoor play area for children within The Park of Mall of Arabia (source: Google Maps Street View).

Public gathering places

The Mall of Arabia has an introverted architecture with solid façades on its exterior and two open courtyards. The first courtyard has a tent canopy covering a food court that opens onto a raised water fountain. The water element acts as a focal point for seating areas of the surrounding cafes and restaurants. The water fountain is an aesthetic feature that encourages outdoor seating and helps with acclimatizing to hot weather. The second courtyard is a recent extension to the mall and has a park and playground. The public gathering courtyard spaces complement the commercial shopping activity. However, designers of the mall seem to have conceptualized the strolling activity of vitrine shopping within the enclosed space as separate from the outdoor gathering space designed for passive and active leisure activities.

Insertion in the urban fabric.

The Mall of Arabia is still organized like an indoor mall as all its corridors are double loaded with shops that are inward oriented and form a closed circular loop. This separation may be beneficial by offering respite for those enjoying the outdoor gathering spaces from the efficient and controlled space inside the mall. It balances spaces of leisure and free movement with spaces of consumption and linear movement. In the end, however, it is not an outdoor shopping mall. Designers intended this contrast between indoor and outdoor spaces to introduce a lifestyle dimension to the mall (yoga platforms, running track, fountain seating and park) that complements the commercial function. They want the mall to be a destination place for repeated visits by 
offering a variety of secondary activities such that mall goers incorporate the mall in their everyday practices in addition to their weekend or holiday shopping. Nevertheless, despite this aim, these new gathering spaces are still appended and subservient to the functioning of the mall as an efficient emporium for consumption. The following figure is a schematic diagram for a model of the mall showing spaces for public gathering in the outdoor courtyards.

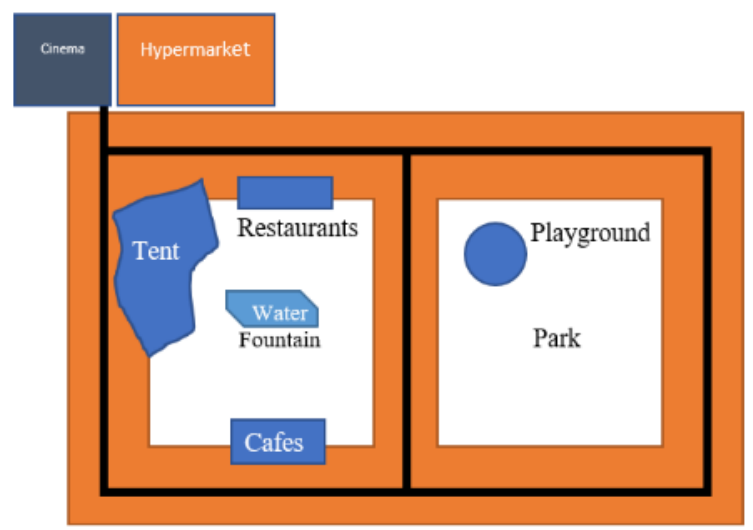

Figure 4. Schematic diagram of the lifestyle model for Mall of Arabia in $6^{\text {th }}$ of October City.

\section{District Mall}

Description / Background

The District Mall opened in 2014 and is located close to Cairo International Airport with GLA of $194,000 \mathrm{~m}^{2}$. It is an open-air mall having a pedestrian friendly environment with year-round family events, kids' activities, and live music and entertainment. It has 243 units for retail, food and beverage, entertainment, and leisure. The food and beverage zone has a stunning combination of over 15 coffee shops and restaurants (International, Italian, and Oriental and Lebanese cuisine) with both indoor and outdoor seating areas. There is an outdoor stage set for live shows and music bands. A main feature of the mall is an artificial lake (see Figure 5) that accompanies the movement of pedestrians along a stone path with a herring bone pattern. The artificial lake offers pleasing views to customers seated in restaurants and cafes surrounding the lake. An island in the middle of the artificial lake is reached by a bridge and leads to a café and an outdoor stage. A sunken pirate ship in the middle of the lake adds interest and a theme to the mall environment. Escape game rooms at Hint Hunt, a franchise, offer social gaming experience. Kids can take a train-on-wheels to tour the mall. The intention behind the design of the open-air mall is to offer a public space of gathering throughout the year for live events, bazaars, music, and street festivals. The slogan in the mall's logo reads: "Where a day is not enough". 


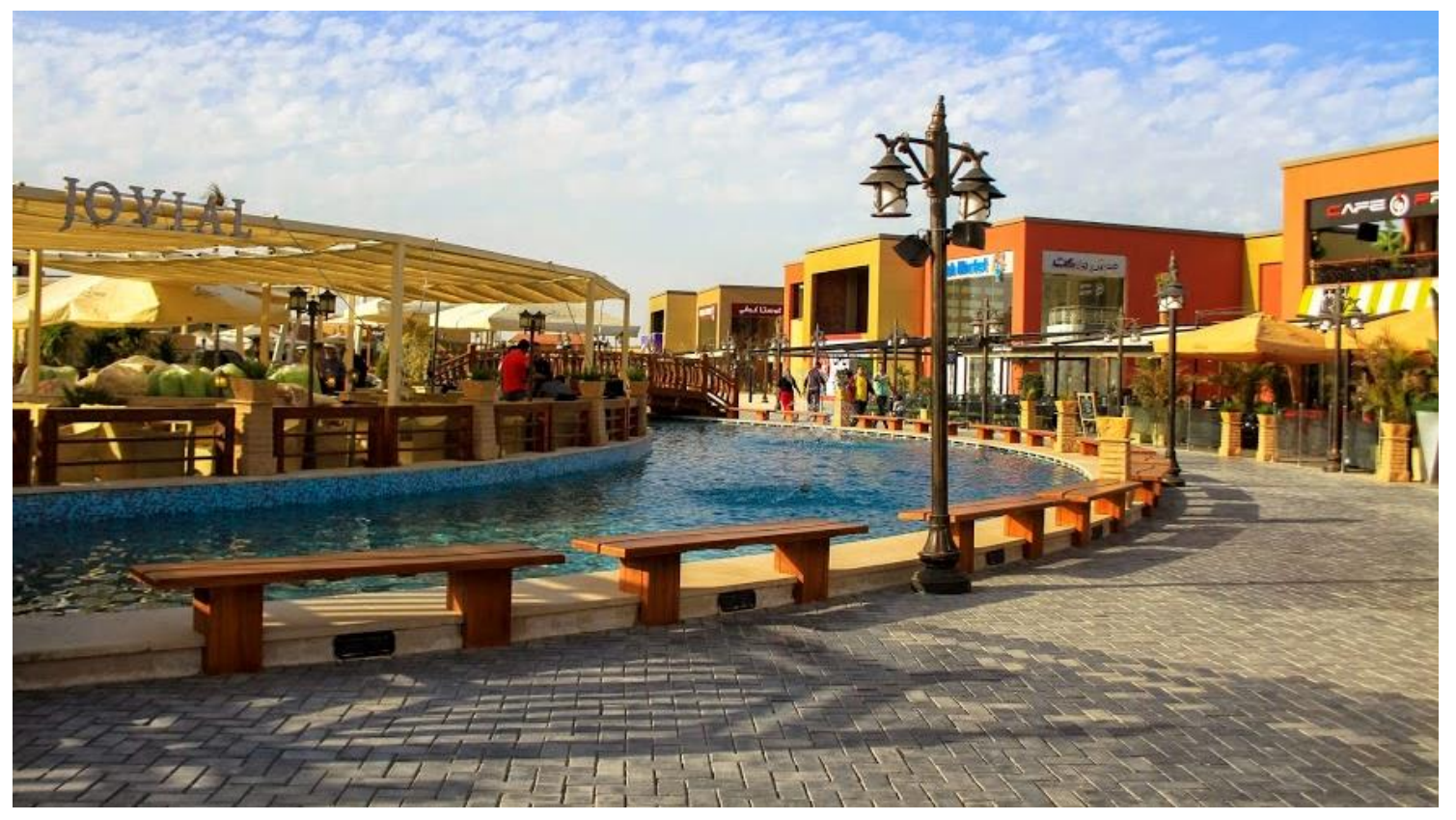

Figure 5. View of the artificial lake, cobbled stone path, and restaurants surrounding the lake in The District Mall.

(Source: User blog https://londoneyablog.wordpress.com/2014/03/31/district-wadi-degla-heliopolis/)

Public gathering places

Reviews by customers see the quality of services in decline compared to when it first opened. Those who frequent the mall lately are seen as low class. It is a nice place for family gatherings, celebration of birthday parties, and photography events as well as being a safe place for kids to play but does not come across as a state-of-the-art mall in regard to the presence of international retail shops. It has a lot of small partitioned shops or kiosks.

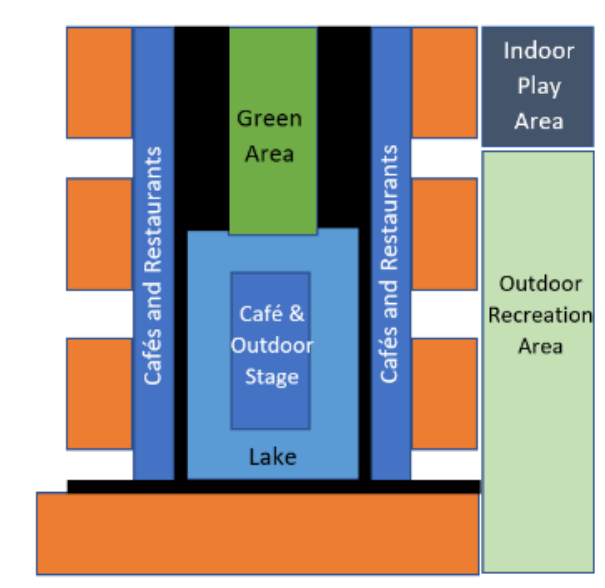

Figure 6. Schematic diagram of the open-air District Mall close to airport

The ambience is noisy and crowded during holidays and weekends especially with the noise of airplanes that take off or land very frequently to the nearby airport. It also has 
limited parking space which is also not free like parking lots in other malls. The District Mall mainly serves as a space of leisure and relaxation than a space for shopping like a typical mall. Figure 6 shows a schematic diagram of public gathering spaces in the mall with the artificial lake as an organizing element for the mall layout.

Insertion in the urban fabric

The District Mall is located in proximity to Cairo International Airport and located just across a private club. Proximity to the airport allows easy access with an influx of tourists and visitors causing crowdedness and a sense of inclusivity with people from many backgrounds and social groups frequenting the mall. The Mall is on the other extreme of mall types, being mainly an open-air mall. The commercial functionality takes a secondary role while leisure and dining functions are primary. Proximity to the private club gives a stark contrast to the public accessibility of the mall space with the private restricted access of the club.

\section{Cairo Festival City Mall}

\section{Description / Background}

Cairo Festival City Mall (CFCM) is a regional shopping centre located in New Cairo and has over 300 stores and 95 restaurants and cafés with GLA of $158,000 \mathrm{~m}^{2}$. It is a shopping, dining, and entertainment hub that offers an indoor-outdoor retail experience for the first time in Egypt. CFCM has a central space that hosts musical shows with a dancing water fountain that represents the core of public gathering and social interaction with restaurants and cafés surrounding the water feature. The fountain is animated with water jets and shooters that provide spectacular performances of water, music, and light. The open outdoor public space encompassing the fountain and complementing the mall, called the Village, has 50 cafés and restaurants, and hosts occasional events, festivals, and live performances in the open-air Amphitheatre that accommodates up to I,200 guests. Because this gathering space is not enclosed, users from different socio-economic levels have more freedom accessing the space (Elhusseiny and Kesseiba, 2019) compared to access of courtyard spaces of the Mall of Arabia. An indoor theatre opened in 2015, the Marquee Theatre with a capacity of I,656 seats, complements the Amphitheatre with international performances and concerts. The main mall has three floors of world-class shops with famous brands, local shops, and kiosks as well as a massive food court that includes international eateries and local delicacies. The main anchor stores are IKEA, a hypermarket and four department stores Marks \& Spencer, H\&M, Zara, and UK retailer, Debenhams. Leisure and entertainment options include trampolines, a climbing wall, a ropes course, an obstacle Ninja warrior course, ice skating, a kids' zone and play areas such as Kidzania, Playdate, Magic Planet and Wiggly Jungle, a pre-school and interactive educational environment, and over 15 cinemas with 4 VIP luxury halls. One could spend on average of four or five hours in the mall in a single visit. 
Karim W. F. Youssef

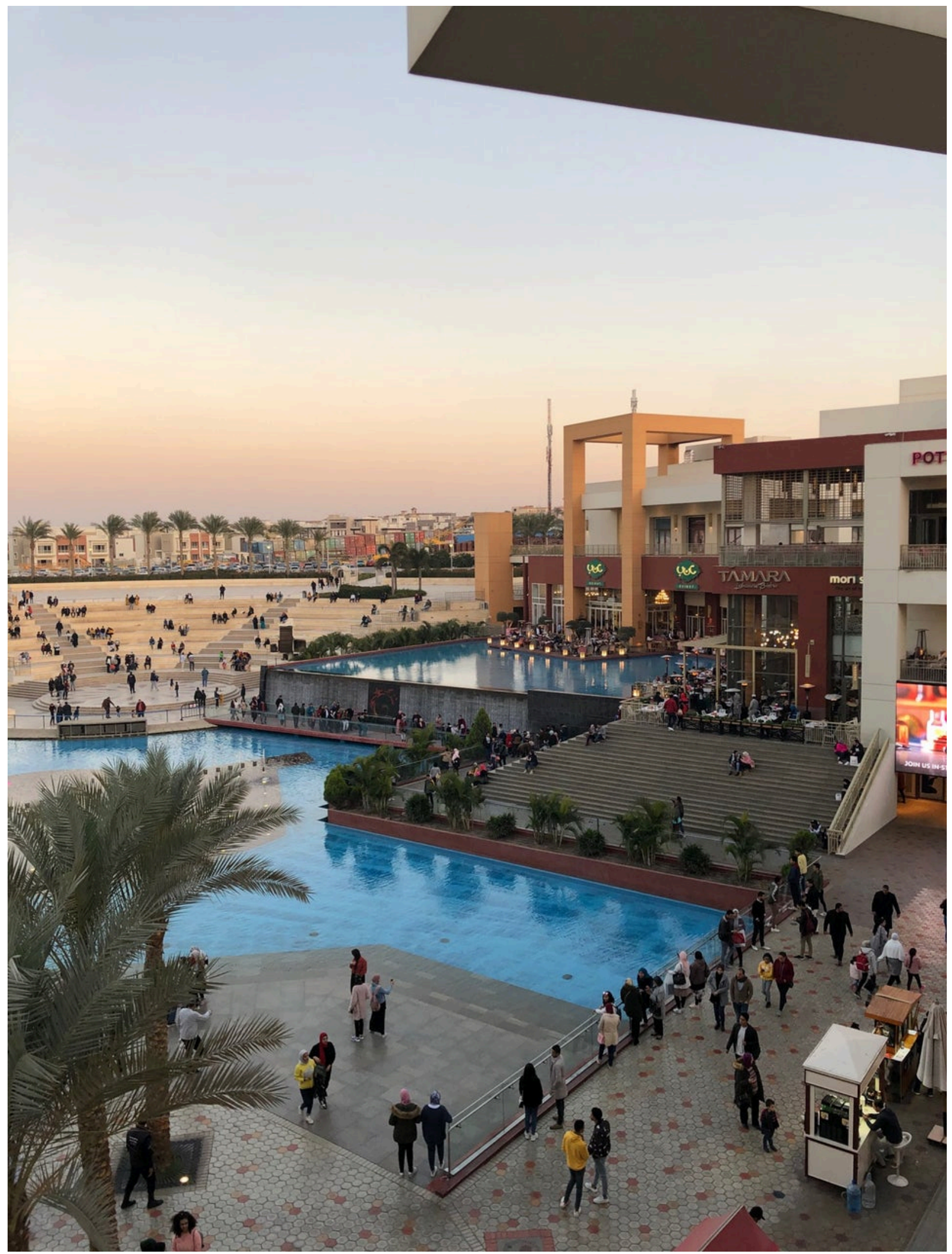

Figure 7. View of CFCM in New Cairo, $5^{\text {th }}$ Settlement.

(Source: Foursquare City Guide - User Photo) 


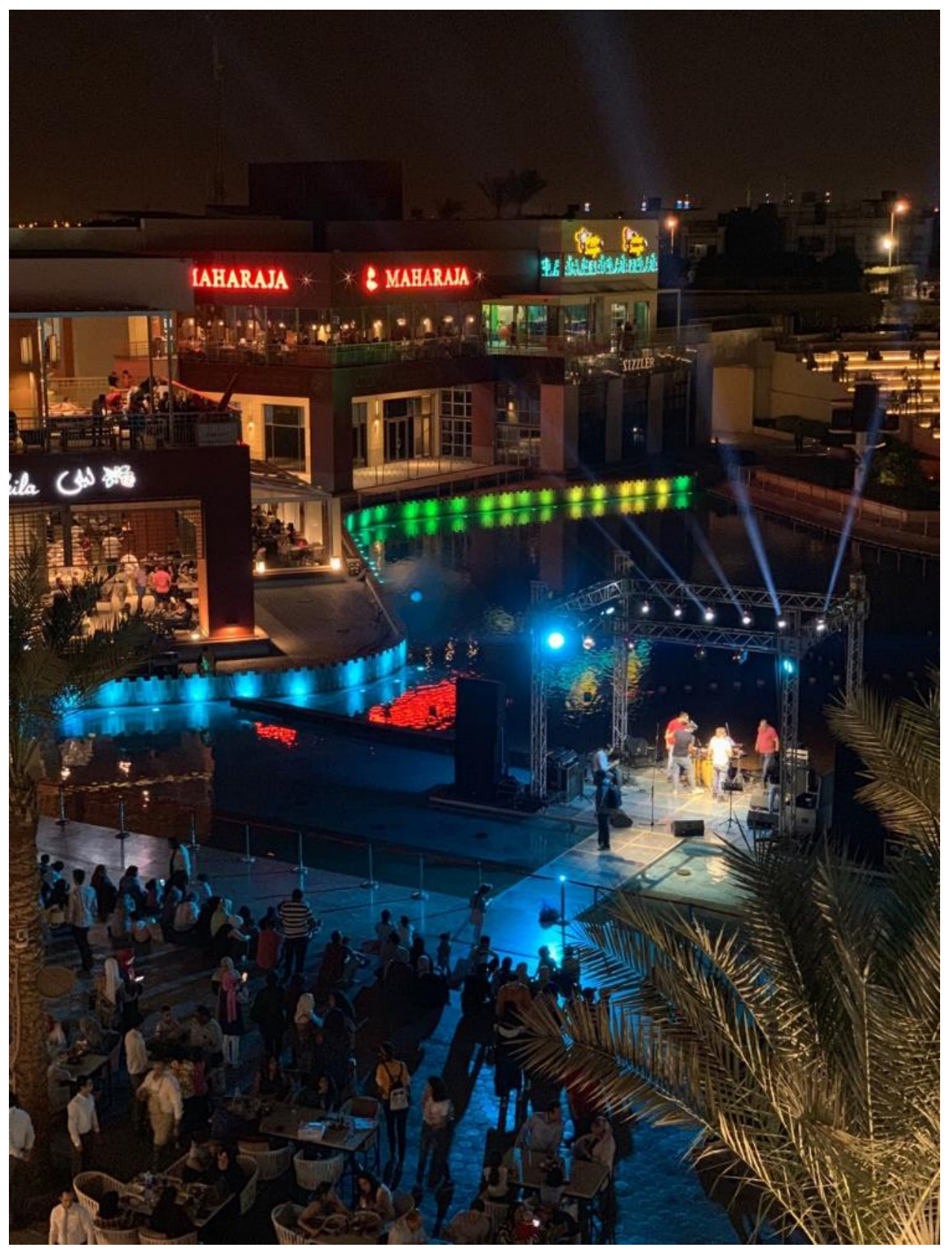

Figure 8. Night view of CFCM showing Amphitheatre far right. (Source: Foursquare City Guide - User Photo)

CFCM plans an expansion called the Festival Avenue of GLA 22,000 $\mathrm{m}^{2}$ (with a 5,300 $\mathrm{m}^{2}$ skylight) opening in 2022, making it the largest mall in Egypt. The expansion will comprise 120 new retail units including 60 international brand luxury boutiques (bringing several new brands to Egypt for the first time) as well as a I,600 $\mathrm{m}^{2}$ Food Hall with 20 new dining options of international cuisine, and a new elevated entertainment complex for games and leisure activities for all age groups. A new mobile application with voice technology using a newly developed Omega platform (AI Futtaim, 2019) will 
combine traditional retail with modern artificial intelligence technology, while also promoting social networking.

\section{Public gathering places}

The following figure is a schematic diagram of CFCM. The public gathering space (fountain, water pool, amphitheatre, seating areas, steps, and stepped platforms) and outdoor retail kiosks and outlets complement the indoor shopping experience. The architecture and form of mall buildings is basic rectangular shapes, not distracting, and acts as a background to the festive and commercial space. Unlike the enclosed experience of the Mall of Arabia or the open experience of the District Mall, the CFCM succeeds in combining the best of both models, the enclosed mall, and the open mall, while expanding the role of landscaping of the public space by including water features on several levels, lighting of exterior stairs, large screens for display of events such as soccer matches and advertisements, and the amphitheatre to encourage lingering in the mall while being entertained. Another factor contributing to the success of the mall is its location in New Cairo serving several old and new residential neighbourhoods. The mall attracts customers such as tourists by capitalizing on the experience of shopping tourism as well as locals who come to the mall on weekends and holidays to experience a lively public space where there is a mixing of cultures.

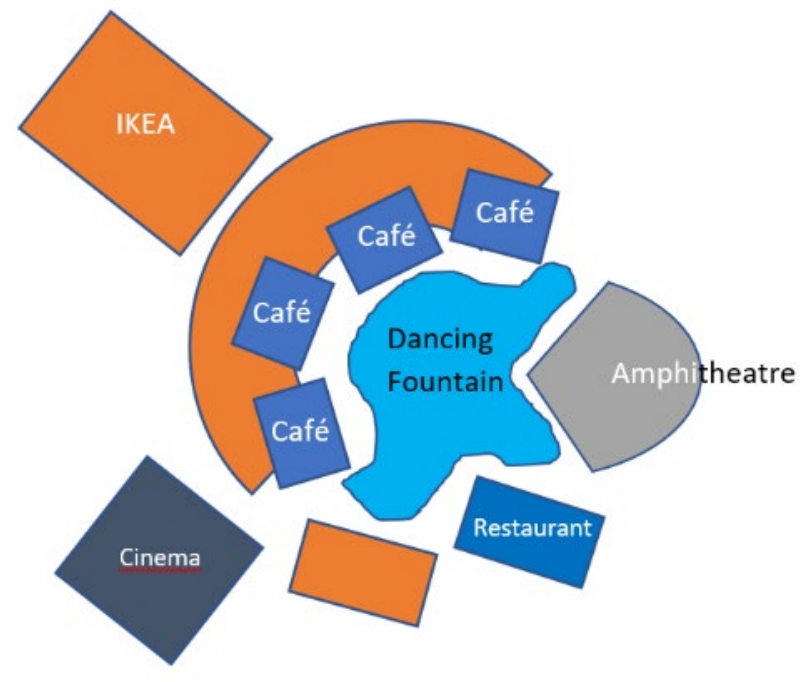

Figure 9. Schematic diagram of CFCM showing the dancing fountain unifying the spatial organization of the mall

Insertion in the urban fabric

CFCM is part of a larger urban project, the Cairo Festival City and thus integrates better than other malls that are conceptualized in isolation as a single project. The CFCM is able through its insertion in the urban fabric to be better integrated and accessible, being placed along the ring road, located in the prestigious $5^{\text {th }}$ Settlement residential area, and close to high-end gated communities. The mall also connects to other retail hubs in the area, forming a larger network of consumption and affluence. CFCM combines the typology of a typical enclosed mall with a larger shopping centre of which it forms a central part. The larger shopping area includes large, big box retail such 
as IKEA. The key role the mall plays in the urban function of the city is evidenced by the recent expansion for the mall that started in the first quarter of 2020, aimed at enlarging the customer base by adding international brands and high-end shopping experience.

\section{Mall of Egypt}

\section{Description / Background}

Mall of Egypt opened in 2017 in New Giza, west of Cairo. It has 350 stores on 2 levels with GLA 165,000 $\mathrm{m}^{2}$, just a little smaller than Mall of Qatar that opened a year earlier, in 2016, with GLA 195,000 m². It obtained LEED Gold certification in December 2019. Modelled after the ski area in mall of Emirates in Dubai, the Mall of Egypt includes the first indoor ski slope in Africa - Ski Egypt (an area of 22,000 $\mathrm{m}^{2}$ and $200 \mathrm{~m}$ slope), with 10 live penguins to raise awareness about Penguins and environmental conservation, and a Polar Express Train ride. It also includes a 16-unit Food Court, a 21 multi-screen Cinema complex and Magic Planet entertainment centre. The mall offers a familycentred sense of community by focusing on entertainment and the experience of the consumer rather than being merely an inert experience from a serial collection of retail shops. Unlike the previous three malls discussed in this article, the Mall of Egypt consists of three themed zones to differentiate the consumer experience strolling within the mega mall.

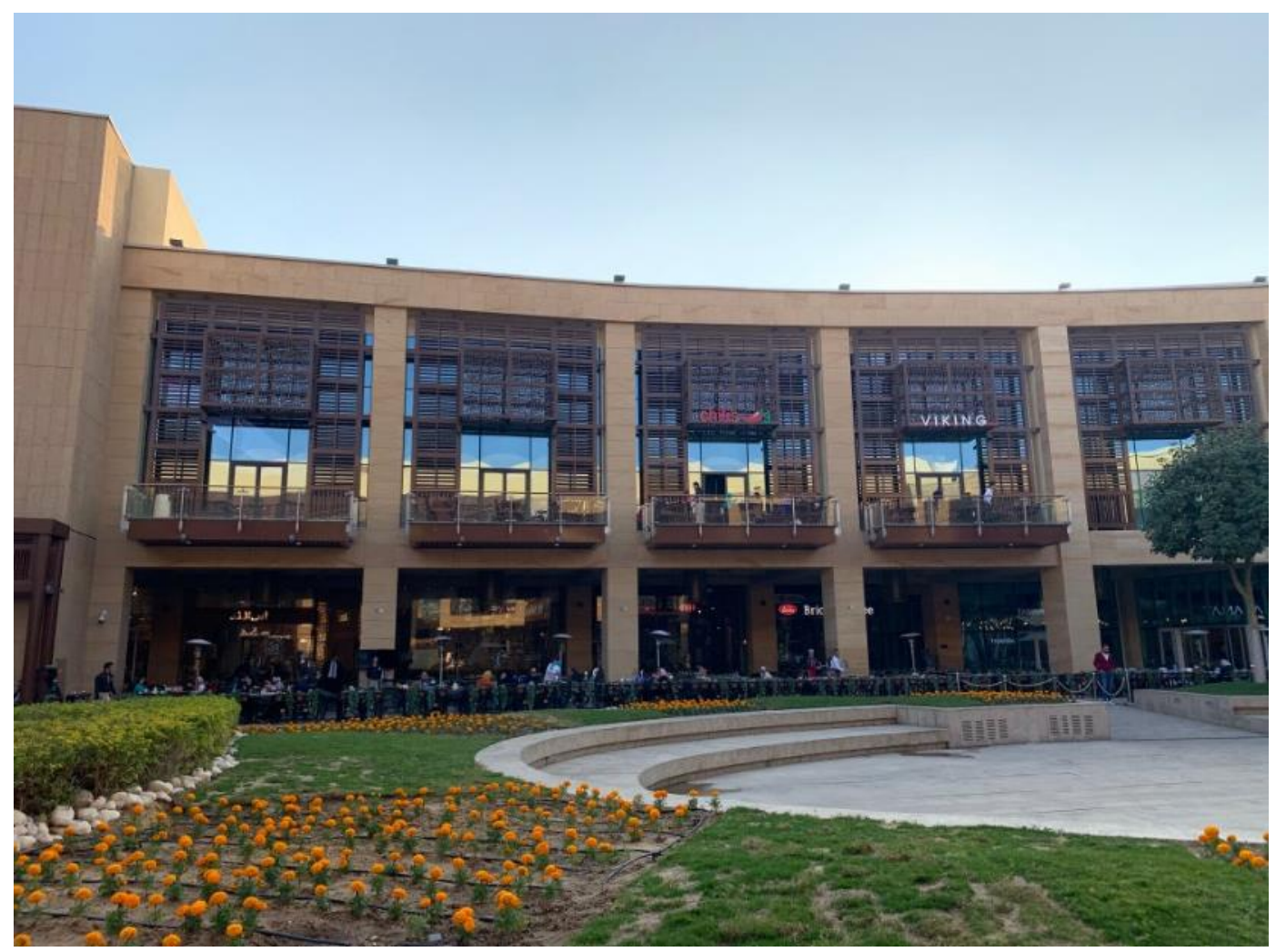

Figure 10. Wood screens combined with panes of coloured glass shade the façades that overlook the open-air plaza with landscaped garden, seating areas, and water feature.

(Source: Foursquare City Guide - User Photo) 
The first zone is called "The City" and mimics a street lined with retail and familyfriendly spaces. The second zone is called "The Desert Valley" which has a central atrium for music and cultural events surrounded by an upscale department store and international retailers. The third zone is the leisure and entertainment zone called "The Crystal" that consists of a family entertainment centre, the cinema complex, and the indoor snow park. At one end of the mall there is an open-air plaza for public gathering called The Plaza (see Figure 10).

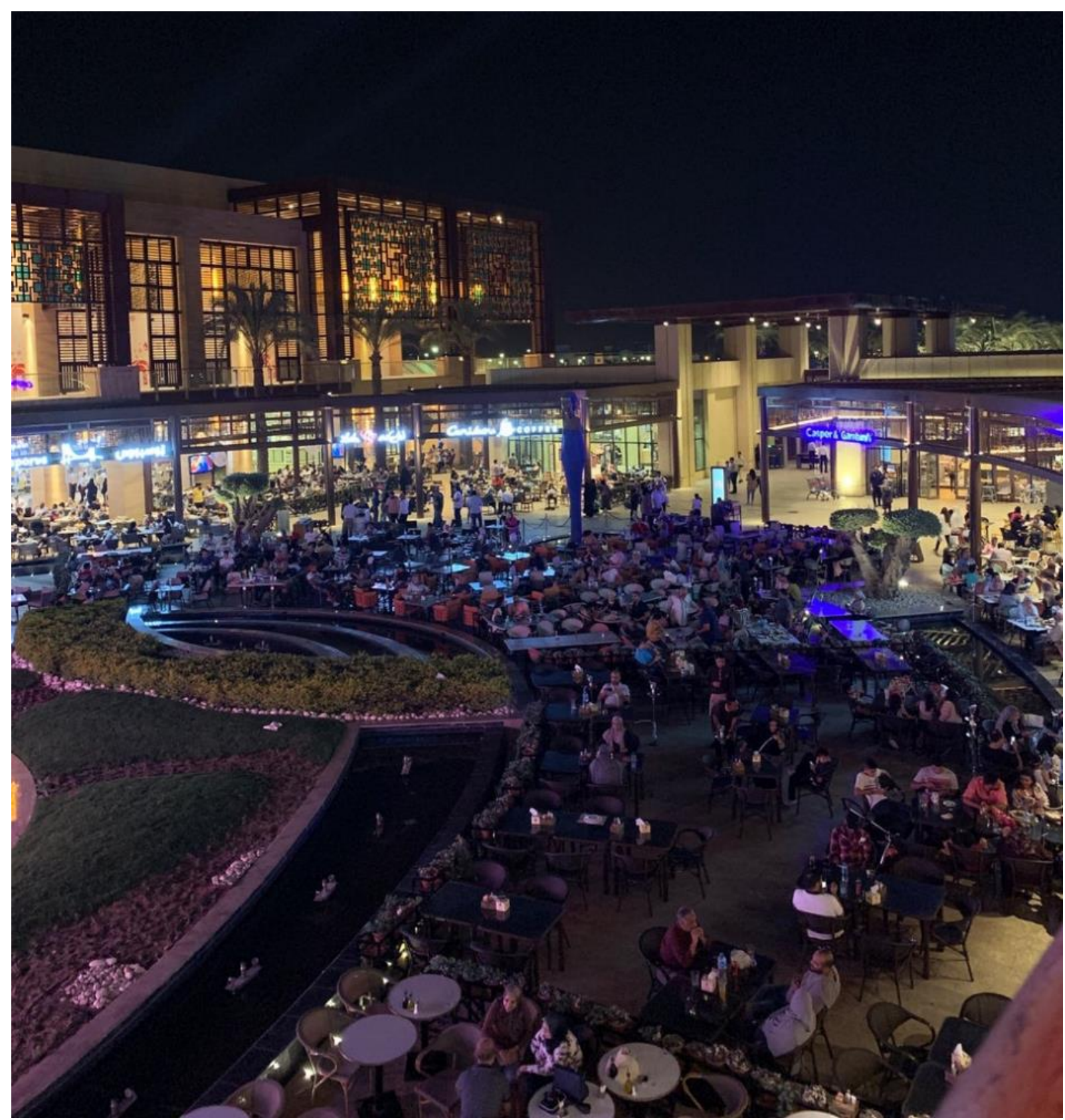

Figure II. View of the plaza at night as a public gathering space. Large screens are mounted in the plaza so customers can follow live soccer matches (Source: Foursquare City Guide, User Photo) 
Public gathering places

The following figure is a schematic diagram of the mall layout. It shows the entertainment zone and the plaza. The plaza has a formal landscape with sculptures/statues and transforms the shopping experience to one of leisure and casual dining. The mall visually connects with the open-air plaza through glass façades and terraces of restaurants. The major focus is on the plaza as a public gathering place to encourage lingering and socialization. The plaza shapes the main façade of the mall and acts as a welcoming entrance. The other four sides of the mall do not integrate open spaces and seem to replicate the negative aspects of North American malls in that they do not add to a lively urban realm or connect with the external landscape as the plaza area does.

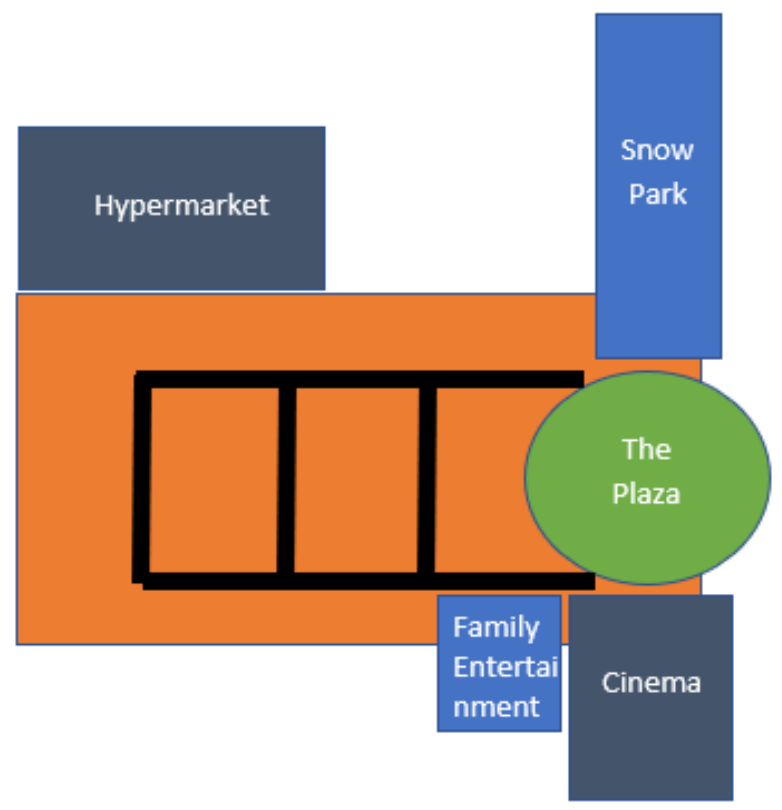

Figure 12. Schematic diagram of Mall of Egypt layout

Insertion in the urban fabric

As the CFCM dominates the east side of the Nile Valley of New Cairo, the Mall of Egypt dominates the west side of the Nile Valley of New Giza. The naming of the mall itself aspires to dominate the whole Egyptian shopping landscape. The Mall of Egypt is even more advantageously located than the CFCM. In addition to integrating with surrounding residential high-end communities such as $6^{\text {th }}$ of October City and Palm Hills, the Mall of Egypt integrates with other hubs of entertainment and a private club. The mall is located just across from the Egyptian Media Production City and further east along EIWahat Road is Dream Land and Dream Park which are major family attractions. The more the urban context is vibrant and active with complementary functions, more visitors are more likely to frequent the mall. 


\section{City Centre Almaza Mall}

Description / Background

City Centre Almaza is built in Nasr City district in the Heliopolis region close to Cairo International Airport, not far from the District Mall. Almaza City Centre is part of a series of malls by Majid Al Futtaim that includes the Mall of Egypt and City Centre malls in Alexandria and Maadi. Following the City Centre Brand, City Centre Almaza has three shopper precincts: the value shopping precinct anchored by a hypermarket, a fashion precinct anchored by international store brands and a couple of department stores, and a leisure precinct anchored by a cineplex, an entertainment centre and an open-air plaza with 12 restaurants. The vision of City Centre Almaza mall is to create a regional mall attracting visitors from the affluent suburbs of Cairo and Giza by merging world-class retail experience with world-class entertainment. The mall opened last year, in September 2019, and has 270 stores with GLA of $103,000 \mathrm{~m}^{2}$. The site is planned to have an expansion in the future. The mall features 23 restaurants, 18-unit Food Court, 9 cafés, a 16-screen multi-plex cinema, a 13,000 $\mathrm{m}^{2}$ hypermarket, and main anchor stores such as Debenhams and Marks \& Spencer, a special indoor area for kids called Little Explorers and a $1,800 \mathrm{~m}^{2}$ area for leisure and family entertainment (Magic Planet, an indoor ride, an indoor trampoline park). It has recently obtained LEED Gold Certification by the US Green Building Council on April 24, 2020, for reducing energy consumption and water use. An open-air plaza called the Restaurant Courtyard has restaurants that offer casual and fine dining experiences surrounded by water features, a pop-up market, and an outdoor area for games (two soccer fields).

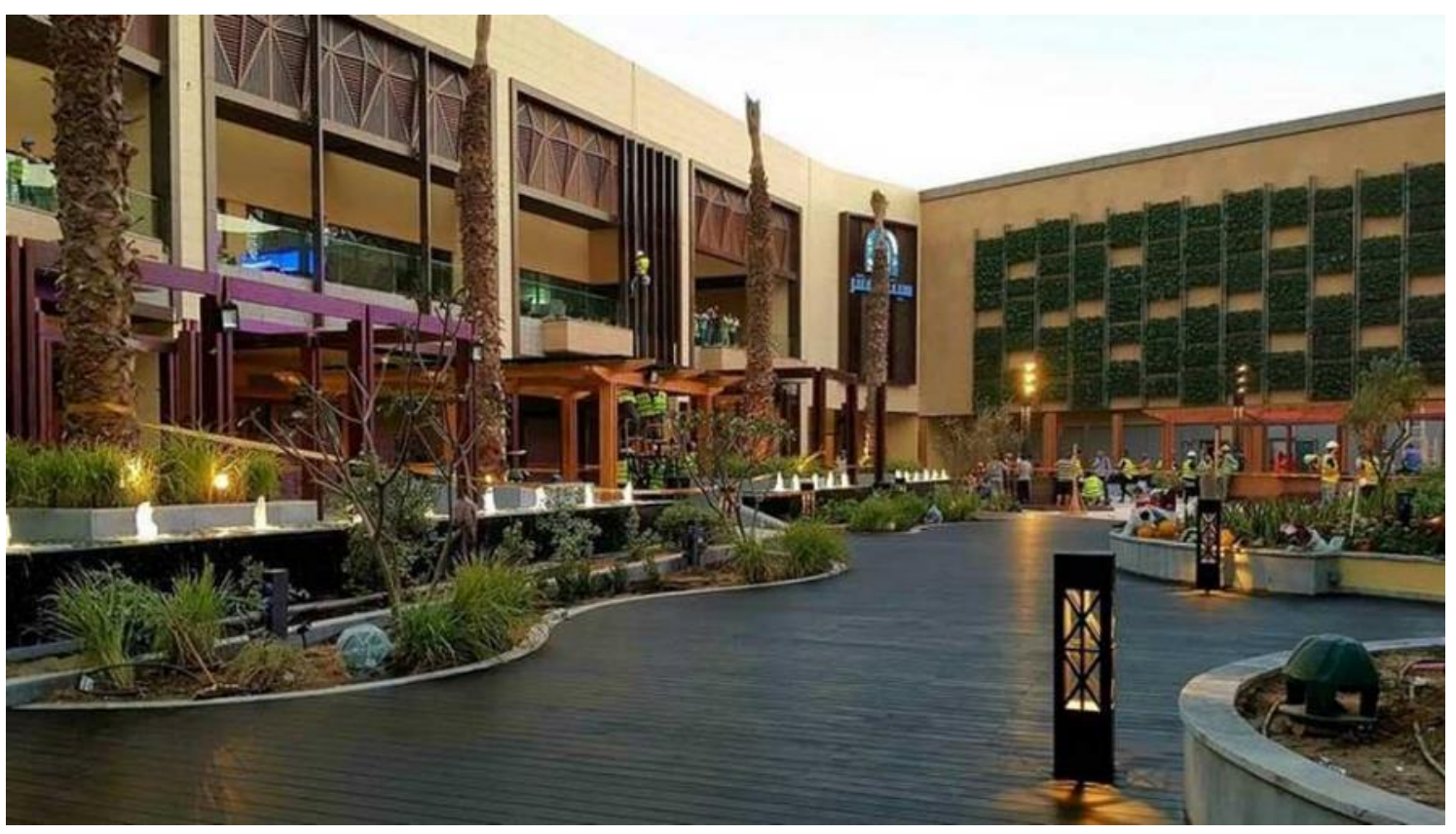

Figure 13. Seating areas and restaurants surrounding the outdoor courtyard of City Centre Almaza. (Source: El-Khawaga, 2019). 


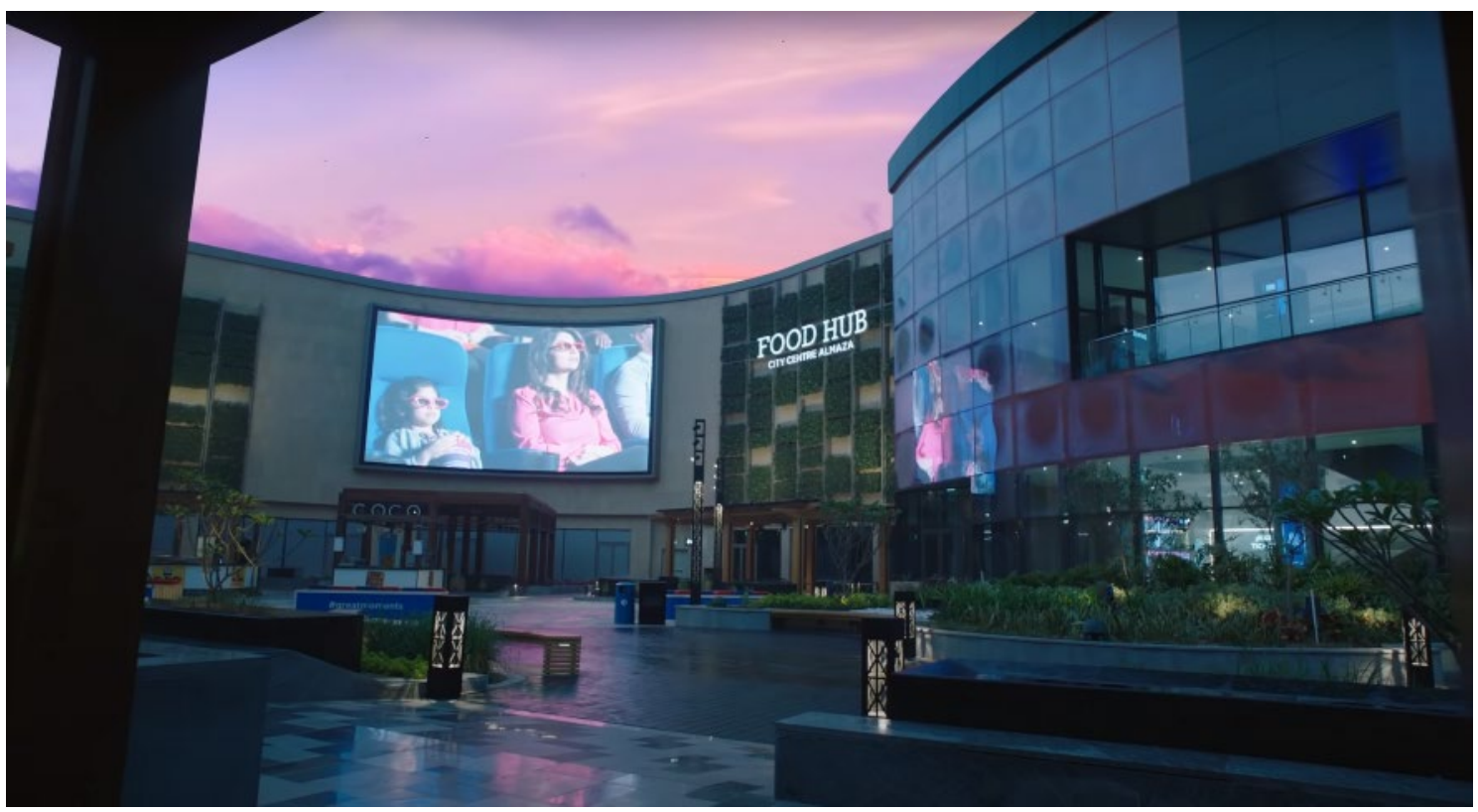

Figure 14. Another view of the courtyard showing seating benches, a large display screen, and the façade of the Food Hub. (Source: City Centre Almaza promotional video).

\section{Public gathering places}

The following figure is a schematic diagram of the mall layout. The diagram follows a typical indoor mall layout with the many negative aspects associated with this typology. There were plans to include a $250 \mathrm{~m}$ ski slope, which would be larger than that in the Mall of Egypt but was not realized. Remarkably, the open courtyard is placed in close proximity to the Cinema and Food Hub. This courtyard is the main socializing space of the mall and contrasts with the rest of the commercial functions of the mall. Unlike the Mall of Egypt, the Family Entertainment area in City Centre Almaza is totally separated from the Cinema.

\section{Insertion in the urban fabric}

The mall is located at the intersection of EINasr Road and EISuez Road. Despite its location at a major arterial intersection, it competes with attracting customers from other nearby malls within the Nasr City area such as City Stars, a mall which dominated the mall landscape in Egypt during the first wave. City Centre Almaza depends on its branding to attract customers. However, it is disadvantageously located in an area that has many light industrial functions, administrative buildings, military institutions, auto dealers, etc. These functions do not synergistically complement the functions of the mall. 


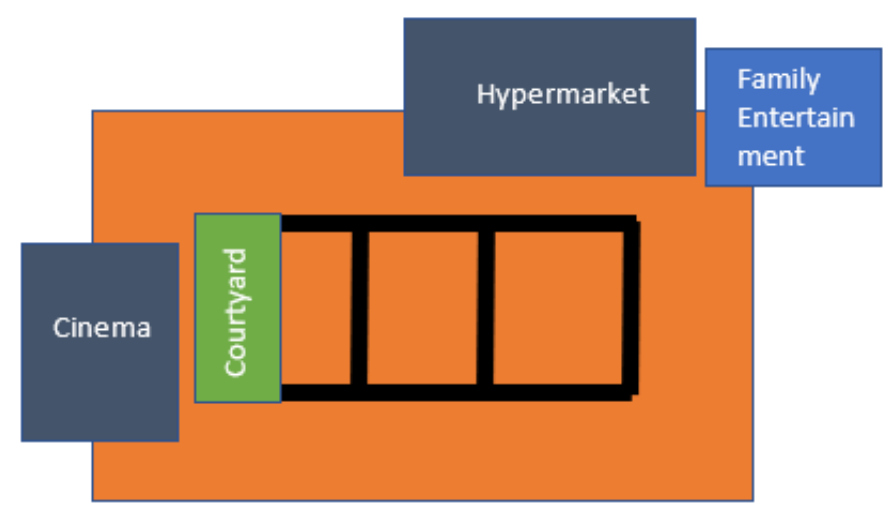

Figure 15. Schematic diagram of City Centre Almaza Mall

\section{Cleopatra Mall}

\section{Description / Background}

Cleopatra Mall is currently under construction. The project has been delayed due to the Arab uprising and political turmoil in Egypt. The concept of Cleopatra Mall presents a unique fusion of interior and exterior spaces to create an attractive shopping and entertainment experience. Cleopatra mall is located in Al Sheikh Zayed City with GLA of $115,000 \mathrm{~m}^{2}$ and features 300 shops on 4 levels with a luxury district in the mall, a fresh market, and a I4-screen Cinema complex, an educational centre for children, active sport facilities where visitors can surf, climb and sky dive, a food court with seating capacity of 2000 and 70 food outlets, a spa, a VIP lounge and a GLA of 10,500 $\mathrm{m}^{2}$ dedicated to leisure and entertainment. A key feature of the design is a $20,000 \mathrm{~m}^{2}$ artificial lake that includes waterfalls, a musical fountain with laser beam displays in the evening, and aquatic shows.

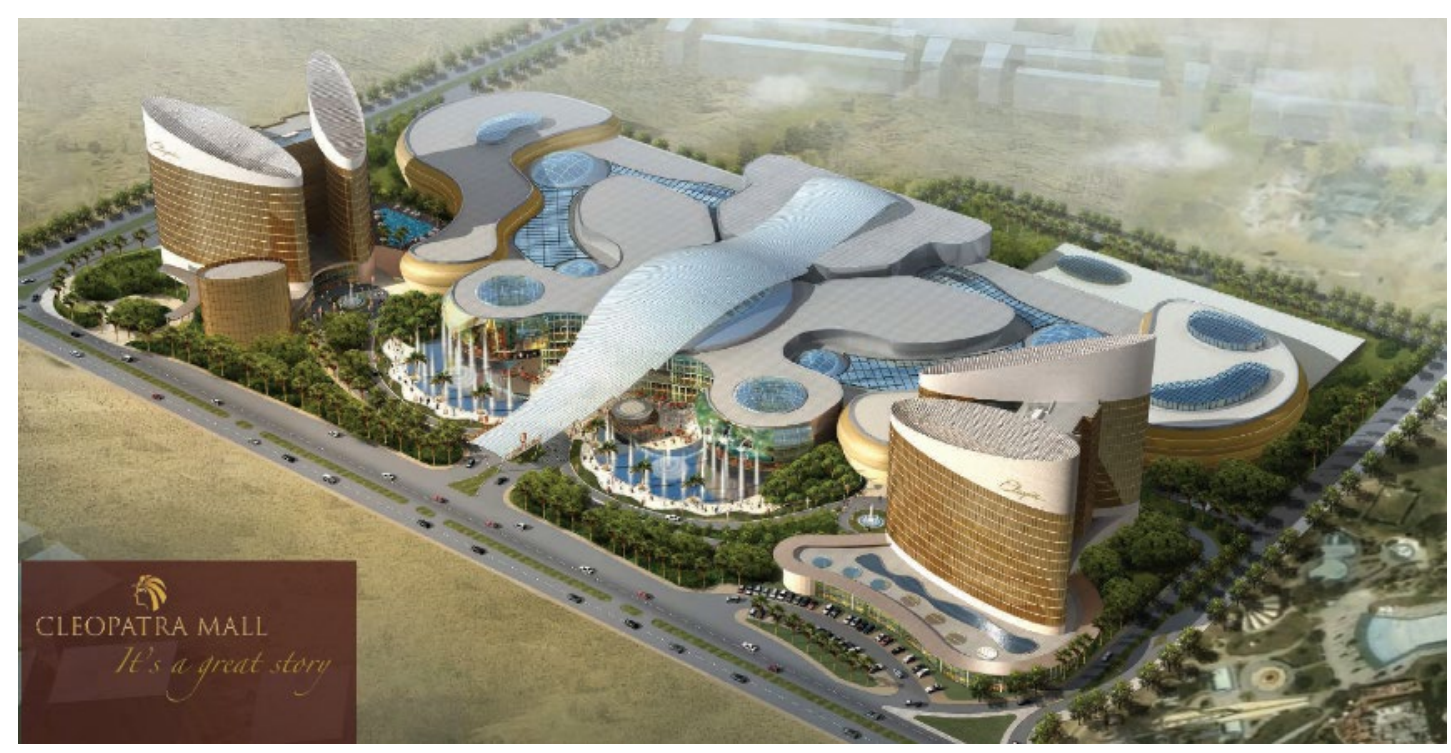

Figure 16. Conceptual rendering of Cleopatra Mall showing a symmetrical design of the retail commercial area flanked by an office and a five-star hotel. (Source: Design International) 
The artificial lake is surrounded by restaurants and has a large multimedia display. A gigantic canopy covers the central area of the mall and spans $200 \mathrm{~m}$. The central Cleopatra court targets the accommodation of 465 shows/events per year. It will be the first mall in Egypt to open 24 hours and offer nightlife entertainment with elaborate light shows and live music bands.

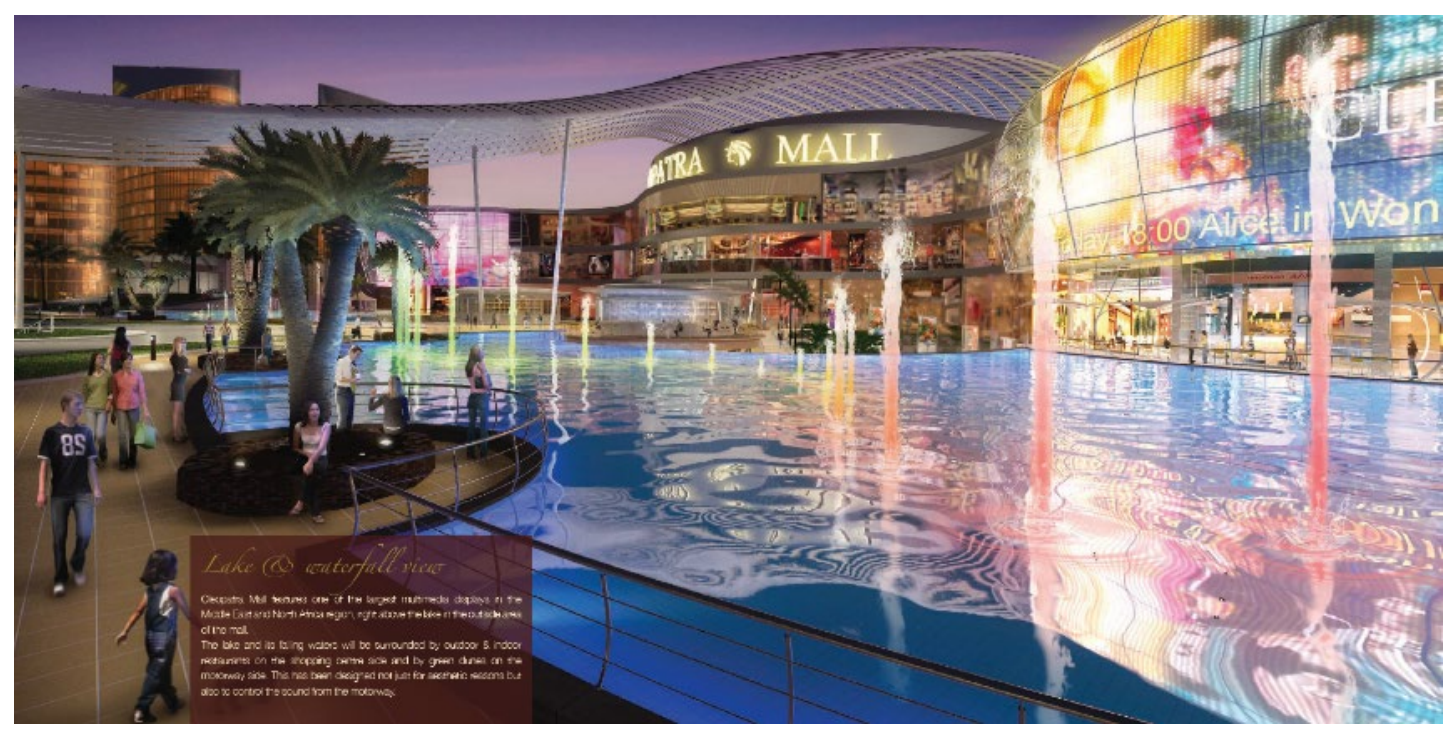

Figure 17. Rendered view of the artificial lake and multimedia display, which will be the largest display in the Middle East. (Source: Design International)

Public gathering places

The following figure is a schematic diagram of Cleopatra Mall.

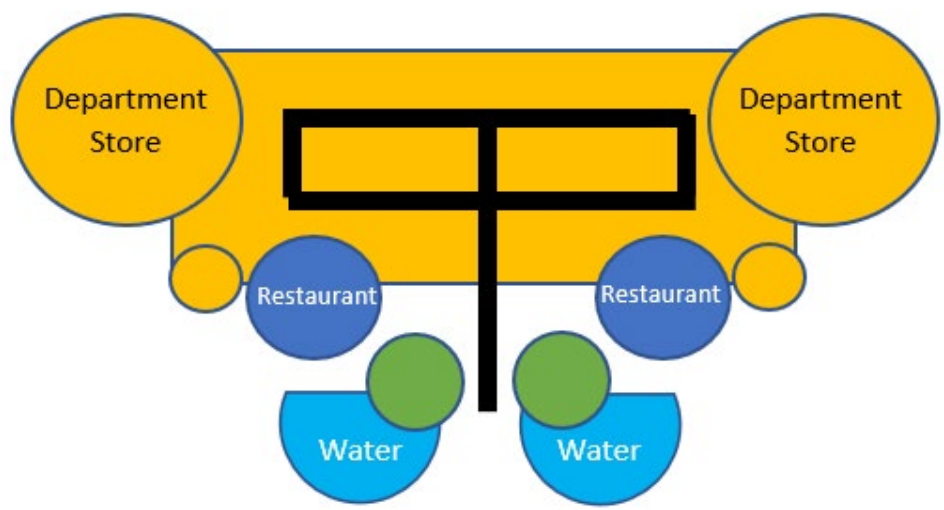

Figure 18. Schematic diagram of Cleopatra Mall showing a symmetrical design reinforced by two anchor department stores and water features as well as outdoor seating areas.

The schematic of the mall shows the emphasis put on the main entrance of the mall to be welcoming and inviting through the use of water elements, sitting areas, and dining areas that herald the function of leisure that is in contrast to the backend half of the mall that emphasizes the strictly commercial and typical layout of an indoor mall. This 
clearly evidences the ambivalence that is shaping the design of malls when bridging outdoor spaces of recreation, entertainment, and leisure with indoor spaces typical of the global mega shopping mall type.

Insertion in the urban fabric

The mall is located within Sheikh Zayed City in New Giza along a major corridor of its intersection with Alexandria Desert Road that connects Cairo to Alexandria. Within the same urban block, there is a campus for Cairo University and a new hospital. The mall is also inserted within a wider commercial area and across from a water park called Crazy Water. The organic shapes of the mall echo the circular street pattern of residential districts in Sheikh Zayed City. The mall is not far from the Mall of Egypt and therefore competes with attracting visitors to the mall.

\section{Four new typologies of public spaces}

We see in these six mega malls several ways of diverging from the typical North American enclosed mall type.

(I) The first type of public space identified in these new Egyptian mega malls is the open-air courtyard, enclosed within the mall. This type is used in the Mall of Arabia and City Centre Almaza. One configuration of the courtyard type is surrounding the courtyard with terraces of casual and fine dining restaurants while placing a landscape feature in the courtyard such as a water fountain or artificial lake to act as a visual and aesthetic focal point. A second configuration of the courtyard type is landscaping the courtyard for active and passive leisure activities such as the expansion of the Mall of Arabia to include an enclosed open-air courtyard that is landscaped with a running track, a park, and a playground.

(2) The second type of public space is the plaza usually placed at a main entrance to the mall. The plaza acts as a meeting, seating, lingering, and gathering space. We see this type in the Mall of Egypt. The plaza in this mall type is defined by the restaurant terraces and by the entertainment zone with cinemas, family entertainment, and the snow park. The plaza acts as a receptacle or large outdoor lobby for the mall. The plaza is landscaped with sporadically placed statues and water features such as small water fountains and a green area. These features are not a visual focal point for the space but rather define the ambience of the plaza. The plaza type is seen in Cleopatra Mall at its main entrance. The plaza type is also identified at the CFCM but has a larger scale and uses different landscaped levels than the Mall of Egypt. The water feature plays a different role in CFCM than in the Mall of Egypt or the Mall of Arabia where the water features are contemplative and aesthetic. The water feature in CFCM animates the open public space by the dancing fountain, the large expanse of water bodies, the waterfall, and the lighting of these water features with coloured lights.

(3) The third type of public space is the theatre or stage for accommodating performances and events. It follows the contemporary trend of eventifying places reinforcing the conceptualization of the city as festive. This type is identified in the District Mall and CFCM. The District Mall is an open-air mall that has a central outdoor 
stage located on an island in the artificial lake. The public space of the open-air mall is also surrounded by terraces of restaurants and cafés, but these terraces experience the movement of mall visitors as they circumambulate the artificial lake. The outdoor stage and the open space of the mall transform the mall into a bustling and large gathering space that almost totally dissociates the leisure experience from the shopping experience. The space is used for shows and live performances. In the case of CFCM, there is an open-air amphitheatre or arena where performances and events take place. It is also a place where a large screen is mounted for mall visitors to watch regional and international soccer matches.

(4) The fourth type of public space is the island in an open-air mall. This type is identified in the District Mall where the central public space is reached by bridges. The island type rhymes well with the pirate theme that is used in District Mall cued by the sunken ship in the artificial lake. In this type, the public space as stage is separated from the public space of the promenade circling the island and abutted with terraces and seating areas of restaurants. This gives separate experiences of the public space for visitors sitting / walking along the perimeter of the artificial lake or watching performances or sitting at the central café located on the island.

\section{Discussion}

The economic climate in Egypt is showing positive signs with political and financial support from Gulf countries and foreign direct investments. Seeing Egypt's potential for growth, companies like Majid Al Futtaim are opening up the Egyptian market to new international retail brands and a new concept of the shopping mall that includes lifestyle, shopping tourism, entertainment, and outdoor public gathering spaces that complement indoor mall spaces. Other new concepts for the mall are adding active leisure experiences (the mall as a lifestyle club or community centre), dazzling sensorial experiences (the mall as a theme park) to engage visitors in other ways than shopping, adding pop-up exhibitions or pop-up markets and street festivals, and the use of technology in the form of innovative artificial intelligence platforms (the mall as a smart hub) or large multimedia display screens for advertisement and entertainment. The new mega malls in Egypt satisfy the needs of youth, women, and families at the physical comfort dimension, the social interaction dimension, and the cultural identity dimension (Abaza, 200I). In this sense, the new mega malls in Egypt are creating a 'third space' for such social groups where they are comfortable becoming 'visible', especially for youth and women. The mall becomes a special kind of 'street' setting (Matthews et al., 2000). The mall in itself represents a suitable, cheap outing, and convenient way to break the daily routine and be immersed in a different world (Farrag et al., 20l0). We need to be reminded that the mall as a place of refuge and comfort is also a place that is, at the same time, reappropriated by visitors through their practices to satisfy their own purposes (Backes, 1997; Reyes, 2016). Some of the new malls in Egypt have demonstrated success of this new integrated model such as the CFCM that has plans for expansion as mentioned above, and the Mall of Arabia that has successfully opened its new expansion. The location of these new mega malls is strategic and is a factor in their success as they are located in the New Cairo and New Giza cities to cater to upscale residential neighbourhoods and gated communities while complementing other 
urban functions such as new universities, and research centres. A couple of the above malls, the District Mall and City Centre Almaza, are located close to the airport to cater to tourists on their way in or out of the country. The retail in the mall is diversified to cater to a wider spectrum of socioeconomic class by providing luxury retail, high range, and middle range as well as including a hypermarket to cater to a wider spectrum of needs rather than just clothing and shoes. So, at the overall scale of the mall, the mall may function as a "social mixer" (Beiró et al., 2018), but at the internal scale of the mall, the high-end expansions will tend to segregate customers depending on which areas within the mall they circulate in, the high-end or middle range. Such a segregation in circulation of customers within the mall has been observed by the researcher in malls in Canada that have added high-end extensions to the mall. $A$ prime example is the Chinook Mall in Calgary, Canada. It is a completely enclosed mall with no open-air courtyards which makes it different from malls in Cairo, but the newly added high-end expansion of the mall segregates the internal circulation of users, dividing users to high income and middle income, or dividing user tastes between haute 'couture' and base 'couture'. The localization / distribution of retail brands within the mall seems to play a role in social mixing / segregation of customers from different socio-economic levels.

It is noteworthy to point out that almost all of these newly constructed contemporary malls in Egypt are located in suburban areas without adequate access by means of public transportation. So, in a way, these malls promote some sort of exclusion of access to the average lower-middle class citizen. Nevertheless, despite their peripheral location, these mega malls have the potential for social mixing and inclusion by virtue of the presence of new public spaces for gathering and the sheer size of the mega malls that requires many visits to explore (Reilly, 1953). Many of these malls have become destinations for families and visitors on national holidays, weekends, and special occasions. The diversity of public gathering places, ranging from courtyards, parks, enclosed atria, and open plazas, gives many options for different social groups to aggregate and feel part of a larger social dynamic. As the research by Beiró et al. (2018) shows, the type of social mixing plays a role in mall selection and results in a socioeconomic distribution of customers visiting each mall. One could extend their research results and make the claim that the type of public gathering spaces integrated within a mall plays a role in potentiality of a mall for social mixing. The more a public gathering space is open and accessible, the more the social mixing and inclusion. Vice versa, the more a public gathering space is enclosed and controlled (over-managed), the less the social mixing. This was evidenced in this paper when comparing the controlled courtyards in Mall of Arabia with the semi-enclosed plaza of the Mall of Egypt, the large plaza of CFCM or with the open-air District Mall. Having large open public places in the mall that allow social gathering and free appropriation of the space results in better inclusivity and social mixing. Further research is needed to corroborate such a claim. The trend in the design of malls to open up the enclosed form (and associated closed loop circulation) to include semi-enclosed and open public areas for social gathering may be a key in rescuing the North American model from the 'death of the mall' syndrome. Death of the mall syndrome refers to the closing of American malls after losing their main anchor stores that would attract users to a mall and generate pedestrian traffic. 
The diversification in retail is paralleled with diversification in entertainment and leisure as well as diversification in food and beverage from restaurants for casual and fine dining to fast food, kiosks, and bars. The new mega malls are aiming to attract children, youth, adults, and seniors through the provision of passive and active leisure activities. The attraction of these social groups operates through an inclusive force, what Allen (2006) calls 'ambient power', that induces certain behaviours or stances. For instance, the Mall of Arabia is encouraging an active outdoor lifestyle through the inclusion of a playground, a park, a running track, and yoga platforms. The Mall of Egypt has brought the first snow park to Egypt for winter activities. It emulates the snow park in Dubai and could be considered as a form of 'reverse tourism' (Miles, 20I2). These leisure activities are complemented with the clustering of restaurants around a public outdoor space such as the Mall of Egypt and the CFCM. The inclusion of a water feature becomes essential not only for aesthetic reasons and social function of the public space but also for physiological comfort as these new mega malls are built in a hot desert climate. However, mega malls differed in the form and scale of implementation of the water feature. For instance, CFCM has a dancing musical fountain and a waterfall, the Mall of Arabia has a smaller scale raised water feature that is contained within one of its courtyards while the open-air District Mall had an artificial lake.

The outdoor public space in CFCM was also more accessible to the public than the Mall of Arabia as people felt more welcome to use the public space without subscribing to any of the restaurant terraces. Hosting outdoor events and concerts is now the norm for mega malls to attract visitors and give consumers a variegated experience of the mall rather than the monotony of strolling in the enclosed indoor commercial retail section. It is important for mega malls to consider better integration of indoor and outdoor spaces. For now, it seems the indoor spaces are for commercial retail functions while the outdoor spaces are for casual and fine dining or for leisure activities. The presence of such a divide may be one of the symptoms of the ambivalence of mall design between retail and leisure (Abaza, 200I). We have seen how the integration between the two was not so evident in the Mall of Arabia. Meanwhile, the design of Cleopatra Mall intends to do just that by means of the large canopy that unites indoors and outdoors.

In regard to the insertion of these mega malls in their immediate context, the mega malls generally turn their back to their surrounding context due to the solid blank façades of large department stores while favouring an internally oriented architecture. Accordingly, the mall is described by Tracy Davis as "a self-contained privately owned city", or by Michael Sorkin as "a city without a place attached to it", liberated from the historical past and cultural traditions (Backes, 1997). This separation from the immediate context is also demonstrated in the large swaths of parking (in the order of 4,000 to 6,500 parking spaces) that surround the mall. These mega malls are horizontally spread out on 2 to 4 levels in contrast to the vertical malls of the 1990s. The horizontal extension of the mall presents a problem of ease of mobility and the necessity of breaking the monotonous retail experience. To overcome that, malls are providing various services such as strollers for kids or wheelchairs for seniors as well as ways for parents to leave their children in a play area while they go shopping or exercising. To break the monotonous experience, one of the mega malls, the Mall of Egypt, designed different themes to three sections of the mall. Another feature the Mall of Egypt implemented to break the monotony is the use of innovative roofs and 
skylights. Natural daylighting of the mall breaks the monotony of the archetypal sterile atmosphere of the enclosed mall and gives the mall a lively atmosphere. A couple of these mega malls obtained LEED Gold certification for innovation, energy efficiency, and water conservation. On this note, the Mall of Egypt deserves a tour dedicated to exploring innovations of roof design and natural daylighting. We also see in the Mall of Egypt the use of wood screens that mix the modern design of the mall with traditional Islamic architecture techniques for shading screens and light refraction through coloured glass panes. Of the six mega malls examined in this paper, those that are strategically located and integrated with the surrounding and complementary urban functions were the most successful. The shopping malls that particularly stand out are the Mall of Egypt, Cleopatra Mall, and the CFCM. Their strategic locations, successful integration within the wider urban context and ease of accessibility promote these shopping malls as substitute city centres for New Giza and New Cairo and as community centres for their surrounding residential districts. Nevertheless, the pseudopublic spaces created within these malls are driven and managed by private interests and corporate control that overshadow the dynamics of a truly public space of the traditional high street.

\section{Conclusion}

The transformation of the mall as a city within a city parallels changes in conceptualizing the city as marketplace to conceptualizing the city as a theatre and to the city as festival. The public spaces of the mall in this transformation do not solely serve the commercial function of the mall but provide the community with a public space for gathering, a public space for performances, and a public space for an active lifestyle while also reminding visitors that the public space is also for creating identities and reproducing social inequalities.

If the 1990s was the decade of malls in Egypt in the order of GLA 40,000 m², the second decade of the 2000s is the decade of mega malls for sizes in the range of GLA 100,000 to almost $200,000 \mathrm{~m}^{2}$. The increase in size still leaves Egypt trailing a little behind recent mall construction in the Gulf Area such as The Avenues, Bahrain in 2017 with 273,000 $\mathrm{m}^{2}$, The Doha Festival City, Qatar in 2017 with 244,000 ${ }^{\mathrm{m} 2}$, and the Yas Mall in Abu Dhabi in 2014 with $235,000 \mathrm{~m}^{2}$. The proliferation of mega malls in Egypt in such a short period speak to the scarcity of public spaces that are suitable for social gathering, social events, and lifestyle activities. An air-conditioned shopping mall is a welcomed place to be in, especially in cities that have hot summer weather and polluted air. The modern shopping mall is an environmentally controlled environment that offers comfort. It is also a welcomed place in cities that suffer from street chaos, traffic, parking, and safety issues. It is a place that offers a sense of order and cleanliness, designed as a destination through creating a sense of place, and a place of escape from the unpredictability of the public street. The shopping mall is a surveilled environment through the use of security cameras, and is a privately managed and controlled environment, a quasi-public space. The shopping mall is an extremely welcomed and needed place in cities in Egypt, especially within new cities constructed in an arid desert climate.

This paper identified a trend common in contemporary mega malls in Egypt, the transformation of the archetypal enclosed shopping mall, mainly focused on commercial retail function, to one that integrates public spaces for leisure, lifestyle, entertainment, 
and dining. This may be a universal strategy to develop the conventional shopping mall concept and counteract the 'death of malls' syndrome prevalent in North America. Mega malls in Egypt are changing the conventional shopping experience from one that is based on a targeted and selective visit to particular stores to one that is based on spatial experience of the mall and social events that encourage recurring visits. The mall becomes a destination that is integral to one's lifestyle and identity. To do that, mega malls in Egypt have resorted to integrating public gathering spaces in their design and associated landscape elements to diffuse the image of the mall from the single-bottom line of corporate profit to the triple-bottom line of environmental and social responsibility.

A general recommendation that this paper makes is that mega malls, along with the diversification of their function and aesthetic image, need to incorporate a variety of types of open public spaces for social gathering and social mixing to cater to different social groups, as well as allow the appropriation of these public gathering places by visitors. The use of landscape elements such as various water features, sculptures, benches, and shaded sitting areas would reinforce the successful functioning of the public gathering places. The challenge that remains for mega shopping malls is how to overcome the ambivalence created by juxtaposing the commercial, cultural, entertainment, and social functions. Will the commercial function of the mall remain the bellwether of those other functions? Stated differently, will mega malls be able to integrate 'consumption in space' with 'consumption of space' (Landman, 2016)? Is cultural diversity within malls being reinterpreted into a commodified version, an 'aesthetic diversity', to use Bauman's term (Bauman, 200I)?

The four typologies introduced within the paper are not mutually exclusive. The enclosed courtyard type could be coupled with a large entry plaza while also having an island 'promenade' with a stage for music and festive performances. The typologies are introduced as corporate strategies to attract consumers and users to the mall. The overall strategy is to enlarge the appeal of the mall to a wider public by adding functions and uses that complement the major retail function of the mall. The configuration and degree of integration of different types of open public gathering spaces with the interior spaces of consumption and retail may well determine the difference between a wellintegrated or polarized functioning of a mall. In either case, a strategic location of the mall within the city, its ease of accessibility, its inclusion within a larger network of complementary and compatible urban projects, and its integration within the larger urban fabric made possible by the mediating role afforded by open public gathering places remain decisive factors in the continued success of the shopping mall-turnedtheme park-lifestyle activity centre building type.

At the urban level, these mega malls, by their sheer size and horizontal extension, act as magnets of activity and as prominent landmarks to their respective cities, contributing to the identity of these cities as places of festivity and lifestyle activity while at the same time offering a place for the reproduction and maintenance of identities. The insertion of large-scale plazas within the design of these mega malls changes the typical introverted character of mall design to an extroverted and welcoming environment. The openness and transparency of spaces invites users to appropriate and frequent the mall as a place of gathering and as a venue for exercising social presence and display. The insertion of courtyards and other types of open spaces allows for a better integration of the mall with the external natural environment, contributing to a diverse 
spatial experience within the mall, rarefying the interior space of these mega malls by connecting them to the natural environment, alongside the ingenious use of skylights as aesthetic features. Nevertheless, such an integration with the wider urban context and immediate natural environment needs to be improved and articulated such that the remnants of the introverted typical shopping mall building type recedes in the background to give way to a fuller realization of a lifestyle activity and entertainment centre that caters to a wider public while at the same time contributing to a livelier urban scene. However, the large swaths of parking areas surrounding these malls still separate and detach mega malls from a fully successful integration with the surrounding urban context. Despite efforts to periodically interrupt parking areas with greenery or walkways, the sheer size of these parking areas positions the mall as an island surrounded by a sea of asphalt. These areas nevertheless may allow for future expansion or grey field development of mega malls, resulting in a much denser development and a more integrated one with the urban environment.

\section{References}

Abaza, M. (200I). 'Shopping Malls, Consumer Culture and the Reshaping of Public Space in Egypt', Theory, Culture \& Society, 18(5), pp. 97-122.

Abaza, M. (2009). 'Egyptianinizing the American Dream: Nasr City's Shopping Malls, Public Order and the Privatized Military', in Singerman, D. and Amar, P. (eds.) Cairo Cosmopolitan: Politics, Culture, and Urban Space in the New Globallized Middle East. Cairo: The American University in Cairo Press, pp. 193-220.

Al Futtaim, M. (Chief Corporate Officer). (2019, March 3). Majid Al Futtaim and i.am+. [Audio podcast]. Available: https://www.listennotes.com/podcasts/the-majidalfuttaim/majid-alfuttaim-and-iam-16THP3eXCS4/ (Accessed: 12 June 2020).

Allen, J. (2006). 'Ambient Power: Berlin's Potsdamer Platz and the Seductive Logic of Public Spaces', Urban Studies, 43(2), pP. 44I-455.

Backes, N. (1997). 'Reading the Shopping Mall City', The Journal of Popular Culture, 3 I (3), Pp. I17.

Baudrillard, J. (1994). Simulacra and simulation. Ann Arbor: University of Michigan Press.

Bauman, Z. (200I). The individualized society. Cambridge, UK; Malden, MA: Polity Press.

Beiró, M. G., Bravo, L., Caro, D., Cattuto, C., Ferres, L., and Graells-Garrido, E. (20I8). 'Shopping mall attraction and social mixing at a city scale', EPJ Data Science, 7(28), Pp. I-2I.

Carmona, M. (2010). 'Contemporary Public Space: Critique and Classification, Part One: Critique', Journal of Urban Design, I5(I), PP. I23-I48.

Clarke, D. B. (2003). The Consumer Society and the Postmodern City. London: Routledge.

Dávila, A. (2016). El Mall: The Spatial and Class Politics of Shopping Malls in Latin America. Oakland, CA: University of California Press.

El-Khawaga, H. (2019). 'City Centre Almaza Opens Doors to Public', Sada Elbalad English, 30 September. Available at: https://see.news/city-centre-almaza-opens-doors-to-public/ (Accessed: I 5 July 2020). 
Elhusseiny, M.-A. and Kesseiba, K. (2019). 'Branding the City: Questioning Mega Malls as New Magnets of Socio-economic Vitality in New Cities around Cairo', in Attia, S., Shafik, Z., and Ibrahim, A. (eds.) New Cities and Community Extensions in Egypt and the Middle East: Visions and Challenges. Cham, Switzerland: Springer International Publishing, Pp. 217-235.

Farrag, D. A., El Sayed, I. M., and Belk, R. W. (2010). 'Mall Shopping Motives and Activities: A Multimethod Approach', Journal of International Consumer Marketing, 22(2), pp. 95-I I5.

Group, O. B. (2010). The Report: Egypt 2010. Oxford Business Group. Available at: https://books.google.ca/books?id=fyTZkEUNIHoC (Accessed: 9 July 2020).

Jacobs, J. (1984). The Mall: An Attempted Escape from Everyday Life. Prospect Heights, IL: Waveland Press.

Landman, K. (2016). 'Shopping malls with quasi-public spaces in Pretoria: Neo-traditional consumption space or controlled village commons?', Town and Regional Planning, 69, pp. 2668.

Matthews, H., Taylor, M., Percy-Smith, B., and Limb, M. (2000). 'The Unacceptable Flaneur: The Shopping Mall as a Teenage Hangout', Childhood, 7(3), pp. 279-294.

McGreevy, M. P. (2018). 'Complexity as the telos of postmodern planning and design: Designing better cities from the bottom-up', Planning Theory, I7(3), pp. 355-374.

Miles, S. (2012). Spaces for Consumption: Pleasure and Placelessness in the Post-Industrial City. London: SAGE Publications Ltd.

Reilly, W.J. (1953). The Law of Retail Gravitation. 2nd edn. New York: Pilsbury Publishers.

Reyes, R.C. (2016). 'Public Space as Contested Space: The Battle over the Use, Meaning and Function of Public Space', International Journal of Social Science and Humanity, 6(3), Pp.20I207. 